\title{
SIP Diyalog Analitiği ve Ses Kaydı Ayrıştırılması Modeli
}

\author{
Adnan OZSOY $^{* 1}$, Fatih ÖZDEMIR ${ }^{2}$, Çağdaş KOPUZ ${ }^{2}$ \\ ${ }^{1}$ Hacettepe Üniversitesi, Bilgisayar Mühendisliği Bölümü, Ankara, Türkiye \\ (ORCID: https://orcid.org/0000-0002-0302-3721) \\ ${ }^{2}$ NETGSM İletişim ve Bilgi. Tek. A.Ş., AR-GE Birimi, Ankara, Türkiye \\ (ORCID: https://orcid.org/0000-0003-0292-3602, https://orcid.org/0000-0002-3608-3747)
}

(Alınıs / Received: 18.06.2019, Kabul / Accepted: 30.10.2019, Online Yayınlanma / Published Online: 30.12.2019)

Anahtar Kelimeler
Telekomünikasyon,
VoIP,
Ses kaydı ayrıştırılması,
SIP diyalog analitiği

\section{Keywords}

Telecommunication,

VoIP,

Voice record decomposition, SIP dialogue analytics
Özet: VoIP ve internet teknolojisindeki gelişmeler ve sunduğu avantajlar nedeniyle, internet üzerinden iletişim çok yaygın hale gelmiştir. Mevcutta kullanılan VoIP birimlerinin özellikle ses kayıt gibi I/O ağırlıklı işlemler sırasında o anki iletişim akışında duraklamalar ve bozulmalara neden olması nedeniyle, iletişimin I/O ağırlıklı işlemler düşünülerek yeniden tasarlanması gerekliliği ortaya çıkmıştır. Bu yayında iletişimin kayıt altına alınması ve ileride kullanıcıya ayrı bir döküm olarak sunulması üzerine karşılaşılan ölçekleme yetersizliklerinin çözümü üzerine bir model sunulmaktadır. İletişimin gerçekleştiği sunucu üzerinde iletişim ile beraber yapılan ses kaydında karşılaşılan sorunlar nedeniyle ortam ağ geçidi trafiğini yansıtma yöntemi ile başka bir sunucuya alınması ve analiz edilerek ses kaydının hangi kiracıya ve kime ait olduğunun tespit edilip eşleştirilerek kayıt edilmesi, ses formatı dönüşümünün yapılması ve kullanıcı ara yüzünden dinlenebilmesi yayın kapsamında incelenmiştir. Ayrıca birden çok işleyiciye adaptif olarak ölçeklenmesine imkan veren bir mimari sunulmuştur. Sunulan modelin programlanması ve işletilmesi sonucu aynı anda işlenebilen görüşme sayısında 5,33 kata kadar bir iyileştirme elde edilmiş, kayıt işlemlerinde yatay ölçekleme sağlanabilmiştir.

\section{SIP Dialogue Analytics and Voice Record Decomposition Model}

\section{Giriş}

İnternetin çokça yaygınlaşması, iletilebilen verinin yüksek seviyelere çıkması ve internet üzerinde maliyet olarak daha ucuza karşılanabilmesi gibi nedenlerden dolayı günlük hayatta kullandığımız birçok teknoloji internet ortamına aktarılmaktadır. Bunlardan bir tanesi de telefon görüşmeleridir. İnternet protokolleri üzerinden ses

\begin{abstract}
Due to the advancements in VoIP and internet technology and the advantages they offer, communication over the internet is adopted widespread. Due to the fact that the VoIP units used in the current process cause interruptions and distortions in the communication flow during the I/O-weighted operations such as voice recording, the necessity of redesigning the communication with $\mathrm{I} / \mathrm{O}$-weighted operations has been emerged. In this publication, a model is presented on the solution of scaling deficiencies encountered upon recording the communication and presenting it later as a separate casting to the user. Due to the problems encountered in the recording of the communication on the same server where the communication is processed as well, forwarding to another server with the method of packet mirroring is studied. Furthermore, analysis of the voice recording to identify the tenant which the recording belongs to, matching the continous call information, recording the call and converting to appropriate audio format are also shown. The proposed model offers an architecture that allows adaptive scaling to multiple processors. As a result of the presented model, an improvement of up to 5.33 times more number of simultaneous calls which leads to horizontal scaling among call recording processes is achieved.
\end{abstract}

(Voice Over Internet Protocol-VoIP) olarak adlandırılan bu teknolojide ses verisi internet üzerinden gönderilmektedir. Hali hazırda internetin hemen hemen her yerde olması sonucu kullanışlı ve ucuz olan bu teknoloji çok hızlı bir şekilde yaygınlaşmaktadır. Özellikle çok fazla sayıda kullanıcı barındıran ve yüksek iletişim ihtiyaçları bulunan şirketler düzeyinde VoIP teknolojisi çok fazlaca tercih 
edilmektedir. Bu denli yaygın kullanımı VoIP için de klasik telefon şebekelerinde olan santral ve diğer destekleyici ürünlerin gelişimini zorunlu kılmıştır.

VoIP alanında destekleyici ürünlerden bir tanesi de son zamanlarda önemi çokça artan VoIP üzerinde gerçekleştirilen iletişimin ses olarak kayıt altına alınması işlemidir. Kayıt altına alınan görüşmeler birçok alanda kullanılabilmektedir. Örnek vermek gerekirse, yaşanan sorunların takibi açısından ses kayıtları geriye dönük belge niteliği taşımakta, yeni işe alınan kişilerin eğitimi açısından eski kayıtlar üzerinden eğitilmesi sağlanmakta, müşteriler ile iletişimde müşteri tercihlerinin belirlenmesi ve yönlendirme teknikleri açısından içerik analizi yapmak gibi birçok konuda iletişim kayıtları kullanılabilmektedir. Bu nedenle son yıllarda iletişimin kayıt altına alınması büyük önem arz etmekte ve hızlı bir şekilde bu alandaki ihtiyaçlar artmaktadır.

Değerlendirilen mevcut sistemlerde konuşma anında bağdaşmayı yapan sistem üzerinden ses kaydı alınması performans (Disk giriş/çıkış (I/O)) konusunda olumsuz etki yaratmaktadır. Sayısal olarak sistemin limitlerine ulaşılması nedeniyle mevcut sistemde kayıt işlemi uygulanan çağrılarda sorunsuz anlık çağrı sayısı düşük seviyelerde kalabilmektedir. Bu işlem ayrıca sesli menüden (anons, bekletme müziği vb.) dinletilen seslerin kalitesini de olumsuz açıdan etkileyebilmektedir. Santralin üzerinde aynı anda gerçekleşen çağrıların tümünün aynı zamanda sunucu tarafından belli parçalarla işlenmemiş (RAW) formattan Waveform Audio File (WAV) formata çevrilerek kaydedilmektedir. Aynı zamanda santrale gelen yeni çağrılara dinletilen ses kayıtları disk üzerinden eş zamanlı olarak oynatılmaktadır. Sunucu üzerinde bulunan disklerin performansı yetmemekte ve ses kaydı dinletme olayına yeterli kaynağı ayıramamaktadır. Dinleyen kişi tarafında bu durum ses kesintisi olarak kendini göstermektedir.

$\mathrm{Bu}$ yayında santral üzerinden yapılacak iletişim faaliyetlerine ilave olarak birçok kullanıcıda ve şirkette ihtiyaç olan, iletişimin kayıt altına alınması ve ileride kullanıcıya ayrı bir döküm olarak sunulması üzerine karşılaşılan ölçekleme yetersizliklerinin çözümü üzerine bir model sunulmaktadır. Bu kapsamda sunulan modelde çok kiracılı bir santral yapısında ortam ağ geçidi trafiğini yansıtma yöntemi ile başka bir sunucuya alınması ve analiz edilerek ses kaydının hangi kiracıya ve kime ait olduğunun Session Initiation Protocol (Oturum Başlatma Protokolü - SIP) ve Session Description Protocol (Oturum Tanımlama Protokolü - SDP) diyaloglarından tespit edilip Realtime Transport Protocol (Gerçek Zamanlı İletişim Protokolü - RTP) ile eşleştirilerek kayıt edilmesi, ses formatı yani kodek dönüşümünün yapılması ve kullanıcı ara yüzünden dinlenebilmesini içerir. Bu kayıt işleminin ise kayıt yoğunluğu ve ihtiyaçları düşünülerek birden çok işleyiciye adaptif olarak ölçeklenmesine imkan veren bir mimari sunulmuştur. Ölçekleme adına sanallaştırma, konteyner yapıları ve iş yükü dağılımı çalışmaları yapılmış olup, I/O kısıtlı bir işlem yükü nedeniyle aynı sunucu üzerinde yapılacak çözümlerden (sanallaştırma ve koyteyner gibi) verim alınamamıştır. Bunun yerine vekil ile bir iş yükü dağılımı sunarak çok sunuculu bir yapı ile ölçekleme sağlanabilmiştir. Yayının geri kalanında şu şekilde ilerlemektedir; ikinci kısımda literatürdeki diğer yayınlar, üçüncü kısımda SIP altyapısı ve kayıt alma işlemi genel bilgi, dördüncü kısımda sunulan sistem modeli, beşinci kısımda sonuç ve ileride yapılabilecek devam niteliğinde çalışmalar ve altıncı kısımda yayın kapsamında alınan destekler sunulmuştur.

\section{Literatür Taraması}

SIP, VoIP'de İnternet Mühendisliği Görev Gücünden (IETF) ortaya çıkan bir standarttır. SIP bir uygulama katmanı kontrol protokolü olup, internet telefonu gibi multi medya oturumlarını (konferanslar) oluşturmak, değiştirmek ve sonlandırmak için kullanılır. Diğer protokollerin aksine, SIP, Hiper Metin Aktarma Protokolü (HyperText Transfer Protocol - HTTP)'ye çok benzeyen ve multimedya iletişimi için büyük genişletilebilirliği olan metin tabanlı bir protokoldür. SIP'in HTTP ve Basit Mesaj Transfer Protokolü (Simple Mail Transfer Protocol - SMTP) ile ilişkisi, pek çok internet elemanını yeniden kullanmasına ve internet uygulamasını altına ses uygulaması getirmesine izin verir. Sadeliği yanında SIP, veri taşıyan aynı İnternet Protokolü (IP) ağı üzerinden ses / video iletmek ve kontrol etmek ve (RTP gibi medya taşıma protokolleriyle birlikte) iletmek için bir mekanizma sağlar [1]. Bu yayında da VoIP üzerinde ses kaydı adına üzerine işlenecek en önemli protokol SIP olacaktır.

Ses kaydı alabilme adına insan konuşmasının alıcılar ile alınarak dijitalleştirilmesi, sayısallaştırılması gerekir. İnsan konuşması, ses sinyalini sıkıştıran kodlama algoritmaları tarafından sayısallaştırılır ve kodlanır. Çoğu konuşma kodlama şemaları, konuşma bölümlerini sıkıştırır ve çerçeveler oluşturur. Yaygın, standart kodlama algoritmaları (G.711 [2], G.723.1 [3], G.726 [4], G.729 [5], GSM [6], AMR [7, 8], AMR-WB [9]) kodlama oranlarında (bit / saniye), kare hızlarında (kare / saniye), algoritmik gecikmelere (milisaniye), karmaşıklık ve konuşma kalitesine (MOS) göre farklılık gösterir [10]. Konuşma kodekleri için önemli bir optimizasyon firsatı, konuşmanın ses aktivitesi ve sessizlik dönemlerinden oluşmasıdır[11]. Bazı kodlama şemaları, sessiz aralarda ses kodlama oranlarını düşürerek iyileştirme sağlamaktadır. Bu işletim moduna sürekli olmayan iletim (discontinuous transmission DTX) denir. Ses yönetimi adına da literatürde çalışmalar mevcuttur [12-14]. [12]'de akustik ve eko gürültülerinin azaltılması,[13]'de ses ve multimedya aktarımında kaliteyi belirleyici bir standart ve testlerin incelendiği bir teknik rapor, ve [14]'de dinamik olarak kod çözücü seçimi adına dağıtık ve merkeziyetçi iki şekilde bir çalışma sunulmuştur. Çalışmamızda ses kayıtlarının mevcut iletişim performansını etkilememesi adına ağ üzerindeki iletişim aynalaması ile farklı bir cihaz üzerinde ses kaydı işlenebilir. Port aynalaması (port mirroring), genellikle şirket odaklı a anahtarlarında ve yönlendiricilerinde bulunan bir işlevdir $[15,16]$. Anahtar veya yönlendiricinin seçilen bağlantı noktalarından geçen trafik, seçilen başka bir bağlantı noktasına yansıtılır. Kopyalanan trafiğin çıktısı için kullanılan port genellikle ayna portu veya Anahtarlamalı Port Analizörü (SPAN) portu olarak adlandırılır. Port aynalama teknikleri, günümüzün orta ve üst seviye Ethernet anahtarları tarafindan desteklenmektedir. Düşük maliyetli bağlantı noktası aynalaması, paket izlerini toplamak için popüler bir 
yöntem haline gelmiştir. Port aynalama çözümünün avantaj ve artıları düşünüldüğünde, piyasadaki çoğu yönetilen anahtarla ücretsiz olarak aynalama özelliği dahil edildiğinden, kullanımının kolay olması ve uzaktan yapılandırılabilmesi nedeniyle düşük maliyetidir. Bu avantajlar, port aynalaması tekniğinin çeşitli amaçlar için paket izleri toplamak için neden popüler bir yöntem olduğunu göstermekte$\operatorname{dir}$ [17-20].

İnternet Üzerinden Ses Protokolü kaydı, ilk önce çağrı merkezleri tarafindan kullanılan ve şimdi her türlü işletme tarafından kullanılan bir telefon kaydı veya ses kaydı alt kümesi olarak literatürde incelenmiştir. Özellikle bu alanda çok sayıda patent başvurusu mevcuttur [22-28]. Yapılan patent başvurularının çağrı kayıt sistemi mimarisi, dağıtık tutulan sistemler üzerinde işlenmesi, olay takibi ile birleştirilmesi, isteğe bağlı kayıt, mobil üzerinde kayıt, ve seçici kayıt üzerine içerikler barındırır.

Akademik yayınlara bakıldığında ise Beuran ve diğerleri VoIP uygulamaları altında veri kaydını bir uygulama olarak incelemiştir [29]. Van Blarcum çağrıdan bağımsız pasif bir işleyici olarak sistemi tasarlamıştır [30]. Gao ve diğ erleri web temelli bir kayıt sistemi teklif etmişlerdir [31]. Cordero ve diğerleri sundukları yayında kayıt edilmiş veri üzerinden işlemler gerçekleştirme üzerine çalışmalar sunmuştur ve otomatik ses tanıma gibi özellikleri kullanır hale getirmişlerdir [32]. Bizim çalışmamızda yapılan çalışmalardan farklı olarak tüm çağrı ve kayıt modelinin sunulması ve mevcut ağ bileşenlerinde aynalama gerçekleşmesi sonucu ses bilgilerinin kayıt edildiği sunucu üzerindeki yoğunluk ve ölçekleme ihtiyacı düşünülerek birden çok işleyiciye ölçekleyerek adaptif bir modeli ve performansını inceleyeceğiz.

\section{VoIP ve Ses Kayıt Süreci}

\subsection{Kayıt işlemi}

Bir telefon görüşmesi, bilgisayar aktarımı, televizyon programı veya herhangi bir türdeki analog veya dijital veri aktarımının içeriğini kaydetmek için iki temel yöntem vardır. İlk yöntem, iletişimin içeriğinden veya özelliklerinden bağımsız olarak, başlatmadan sonlandırmaya kadar her iletişimin kaydedilmesinden oluşan "günlük kaydı-logları" dır. Günlük kaydı iletişimin içeriğinden ve özelliklerinden bağımsız olduğundan, belirli bir iletişimin gözden geçirilmesi gerekiyorsa, her iletişimin kaydedilmesi gerekir. Bununla birlikte, her iletişimin kaydedilmesi, kayda değer miktarda depolama alanı gerektirir.

Bir aktarımı kaydetmenin ikinci yöntemi ise, belirli bir koşul veya olayın meydana gelmesi üzerine bir aktarımı kaydeden "olay odaklı" kayıttır. Bazı durumlarda kayıt koşulu, aktarımın başlangıcı olabilir (birinci yöntem), diğer durumlarda olay aktarım sırasında gerçekleşir (örneğin, kullanıcı bir "kayıt" düğmesine basıldığında olduğu gibi). Kayıt belirli bir zamanda başladığında ve bittiğinde olduğu gibi diğer olaylar zamana bağlı olabilir. Bir olaya dayalı bu kayıt sisteminin bir zorluğu, kaydı başlatan olayı uygun şekilde tanımlayabilmektir. Aşırı derecede geniş tanımlanmış bir olay çok fazla gereksiz yayını kaydedebilir. Olay kaynaklı kaydın başka bir dezavantajı, olayın gerçekleşmemesi veya yanlış zamanda gerçekleşmesidir; bu, aktarımın içeriğinin tamamının kaydedilmemesine neden olur. Yine bir başka dezavantaj, olayın aktarımın başlamasından sonrasına kadar gerçekleşememesi (ya da gerçekleşmemesi) halinde, olaydan önce gerçekleşen aktarımın kaydedilmemesidir. Bu olumsuz durumlar nedeniyle en çok tercih edilen birinci yöntemdir ve bu yayında ilk yöntem olan her türlü yayının kaydı üzerine bir çalışma yapılacaktır.

\subsection{Kod çözücü (kodek) işlemleri ve ses kaliteleri}

Yayın kayıtlarını dijitalleştirilmesi adına kod çözücü işlemlerinin yapılması gerekmektedir. Bunun için mevcut kullanılan kod çözücü işlemleri ve ses kaliteleri incelenmiştir. Her kod çözücünün kendine göre özellikleri mevcuttur ve araştırılan kod çözücüler hakkında ulaşılan bilgileri sıralamak gerekirse;

- G711: Mevcut iki türü, U-law ve A-law, vardır. Kuzey Amerika ve Japonya'da daha çok U-law kullanılmaktadır. A-law ise tüm dünyada genel olarak yaygındır. G.711, 64 kbit/s'de kaliteli ses sağlayan dar bant ses kodeğidir. Kablosuz ağlarda eğer bant genişliği problemi yoksa tercih edilir.

- G729: 10 milisaniyelik bir çerçeve uzunluğu kullanan, telifsiz, dar bantlı bir ses verisi sıkıştırma algoritmasıdır. Ses dosyalarını 8 Kbps'e kadar küçültebilmektedir. Ses kalitesinde çok az bozulma oranı sağlaması tercih etme nedenleri arasındadır. Ücretli bir kod çözücü olması olumsuz yanlarından biridir (32 bit sürümleri hariç)

- GSM: Ücretsiz olarak kullanılabilecek en iyi sıkıştırma oranı veren kod çözücülerdendir ve 13 Kbps'e kadar sıkıştırma oranı vermektedir.

- G722 : HD ses kalitesini 64 Kbps sıkıştırması ve mobil işletim sistemleri (Android ve IOS) tarafinda kararlı ve ücretsiz sürümleri avantajlı yönleridir.

\subsection{Port aynalama}

Port aynalama teknikleri, günümüzün birçok orta ve üst seviye Ethernet anahtarı ile desteklenmektedir. Her yerde ve düşük maliyetli bağlantı noktası aynalaması, paket izlerini toplamak için popüler bir yöntem haline getirmiştir. Yaygın kullanımına rağmen, bu izleme yönteminin ölçülen ă trafiği üzerindeki etkileri hakkında çok az çalışma bildirilmiştir. Özellikle, gecikme ve titremenin (tonlama fark1), paket yeniden siralama ve paket kaybı istatistiklerinin her birine odaklanıyoruz. Port aynalama yöntemini, fiber ayırıcı gibi pasif bir test erişim noktası (TAP) ile izlenen bir bağlantıya yerleştirmekle karşılaştırabiliriz. Pasif bir TAP'ın izlenen trafiğe şeffaf olmasına rağmen, port aynalama popülaritesi sınırlı kurulum kesintisinden ve (potansiyel olarak) daha kolay yönetimden kaynaklanmaktadir.

\subsection{Ses kayıt eşleştirmesi}

Ses kaydının port aynalama sonucu bir diğer sunucu üzerine kopyalanmasıyla bir çok iletişim akışının aynı 
sunucuda bulunması durumu ortaya çıkar. Bu nedenle ses kayıtlarının hangi kiracıya ait olduğu ve kimler arasında olduğunun belirlenmesi gerekmektedir. Bu eşleştirme işlemi için SIP ve SDP [1,33] diyaloglarından kiracıların tespit edilip RTP [34] paketleri ile ses kayıtlarının eşleştirilerek kayit edilmesi gerekmektedir.

Multimedya telekonferansları, IP üzerinden sesli çağrıları, video akışını veya diğer oturumları başlatırken, medya ayrıntılarını, aktarım adreslerini ve diğer oturum açıklaması meta verilerini katılımcılara iletme zorunluluğu vardır. SDP, bu bilgilerin nasıl taşındığına bakılmaksızın bu bilgiler için standart bir sunum sağlar. SDP yalnızca oturum açıklaması için bir formattır - bir aktarım protokolü içermez ve Oturum Duyuru Protokolü (SAP), Oturum Başlatma Protokolü (SIP), Gerçek Zamanlı Akış Protokolü (RTSP), Çok amaçlı internet posta uzantılarını (MIME) kullanan elektronik posta ve HTTP dahil olmak üzere uygun farklı aktarım protokolleri kullanılması amaçlanmıştır [33].

RTP etkileşimli ses ve video gibi gerçek zamanlı özelliklere sahip veriler için uçtan uca dağıtım hizmetleri sağlar. Bu hizmetler, yük tipi tanımlamasını, sıra numaralandırmayı, zaman damgasını ve teslimat izlemeyi içerir [34].

\section{5. Ölçekleme}

Çağrı kayıt esnasında kalite problemi yaşamadan ölçekleme ve daha çok kullanıcı verisi işleyebilmek için, yaptığımız çalışmalarda görülen her 150 aktif çağrıya ulaşıldı ğında yeni bir sunucu kurulması gerekmektedir. Bu işlemler ise hem işletme maliyetini hem de donanım maliyetini artırmaktadır. Sistemler performans olarak zorlanmaya başladığında ise SIP diyaloglarında kopmalar olmakta ve bu da mevcut çağrılarda kopma ve ses kaydı alınamamasına sebep olmaktadır. Bu nedenle daha yüksek ölçekli çağrı sayısına ücretler ve iletişim kalitesi adına daha verimli bir şekilde ulaşmak için mevcut sistemlerden farklı bir çözüme ihtiyaç duyulmaktadır.

\section{Model}

Bu bölümde santral üzerinden yapılan iletişim faaliyetlerinin kayıt altına alınması ve ileride kullanıcıya ayrı bir döküm olarak sunulması üzerine literatürde de karşılaşılan ölçekleme yetersizliklerinin çözümü üzerine bir model sunulacaktır.

Öncelikle Şekil 1'de genel olarak tercih edilen kayıt işleminin ve iletişimin tüm akış diyagramını görmekteyiz. Bu şekilde görülebileceği gibi yapılan bir aramada santrale gelen çağrı özel santrak (PBX) üzerinden ilgili uca iletilmektedir. $\mathrm{Bu}$ kapsamda ilgili uca yönlendirilen çağrının işlendiği sunucu üzerinde hem çağrı işlemleri hem de kayıt işlemi yürütülmektedir. Bu şekilde işlenen çağrının en temel sorunu ölçekleme problemleri ve çok az çağrıda dahi kayıt işleminin mevcut iletişim işlemlerini aksatmasıdır. $\mathrm{Bu}$ şekilde sunulan işlemede sunucu üzerinde kayıt işleminin farklı yazma hızına bağlı üç farklı disk üzerinde yaptığımız testlerde Şekil 2'deki sonuçları aldık. Birinci disk 10bin RPM hızında veri aktarım hızı 6Gbps, ikinci disk 15bin RPM, 12 Gbps hızında ve üçüncüsü ise SSD bir disktir. Tüm diskler RAID 10 yapısı ile

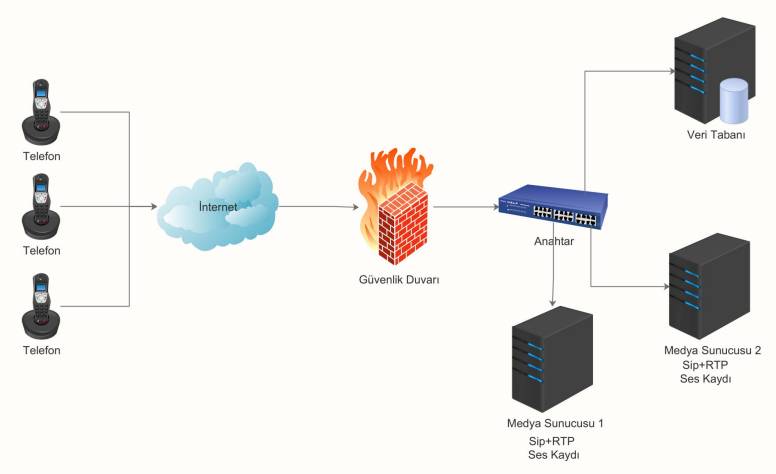

Şekil 1. Kayıt ve çağrı işlemlerinin beraber yürütüldüğü model.

test edilmiştir. Sunucu olarak Dell R730 Server 2640 V4 X2 işlemci üzerinde 32 GB Ram kullanılmıştır. Burada sistemin çağrı başlatabilme ve başlatılmış çağrıların kayıtlarını yapabilmeleri incelenmiştir. Bunun için kullanılan Asterisk programı bir anda yüksek sayıda çağrıya çıkmamızı kısıtlamaktadır ve birinci saniyede 10bin ve 15bin ve SSD diskleri üzerinde sırasıyla 10,19 ve 22 çağrı sayılarına çıkabildik. Zaman ilerledikçe Asteriskin başlattığı çağrıların sayısı artış göstermiş olup 20nci saniyede gene sırasıyla 70,110 ve 150 çağrıya ulaşılmıştır. Bu noktadan sonra ses iletişimde ve kalitesinde bozulma olmadan artık daha fazla çağrı artışı sağlanamamıştır. Her ne kadar daha fazla çağrıya çıkılabilse de çağrı sesinde bozulmalar nedeniyle çağrı iletişiminde kalitesizlik oluşmaktadır. Ses kalitesinin bozulmadan daha fazla sayıda çağrıya çıkamamamızın açık olarak görülen en önemli faktörü kayıt işlemlerinin I/O istekleri nedeniyle kısıtlanmasıdır. Bu sonuçlara bakıldığında en yüksek sonuçlara üç disk arasında en hızlı olan SSD disklerde dahi 150 çağrıyı geçememekteyiz ve bu rakamlar mevcut iletişim alt yapılarını ve santral hizmetlerinin kullanım oranları düşünüldüğünde çok düşük kalmaktadır.

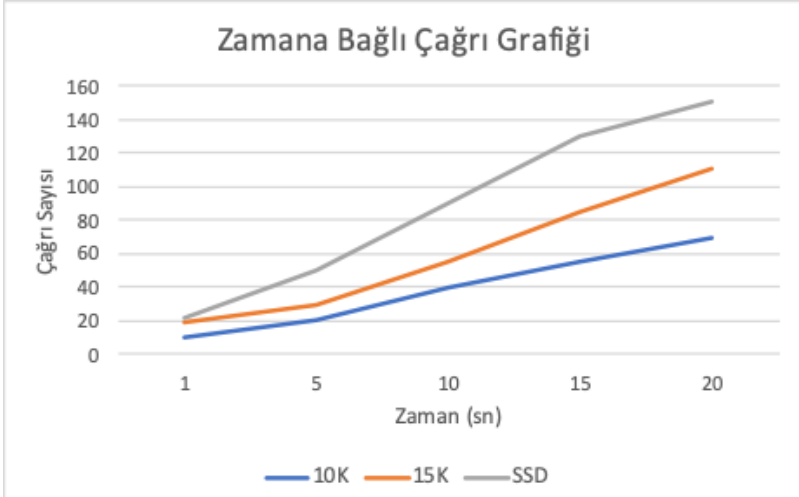

Şekil 2. Kayıt ve çağrı işlemlerinin beraber yürütüldüğü model performans testleri.

Bu modeldeki en temel problem I/O işlemlerinin mevcut sistemdeki diğer işlemleri engellemesidir. I/O yani ses 


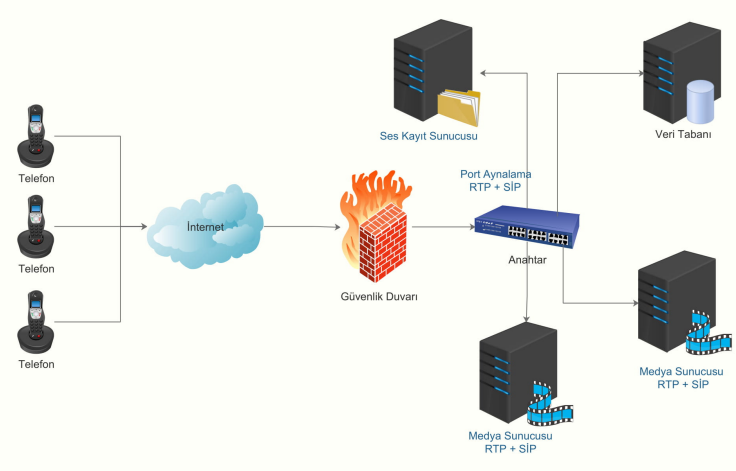

Şekil 3. Kayıt ve çağrı işlemlerinin ayrıştırıldı̆̆ı model.

kayıtlarının diske yazımı işlemini ayırabilirsek yani mevcut sunucu dışına alabilirsek çağrı başlatma ve işletme açısından I/O dar boğazından kurtulmuş olacă̆ız. Bu çözümü işletme adına Şekil 3'de verilen yeni modeli teklif etmekteyiz. Bu yeni modelde yapilan bir aramada santrale gelen çağrı PBX üzerinden ilgili uca iletilmekte fakat çağrının geçtiği anahtar üzerinde bir aynalama yapılarak mevcut çağrı kayıtları dışarıdaki bir sunucuya aynalanmaktadır. Bu şekilde bir sunucu sistem üzerinde ağırlık oluşturan I/O yani kayıt işlemlerini ayrıca işleyebilecektir. Bu modeli gerçekleştirebilme adına 5 ana işlem gerekmektedir (Şekil 4). Bir sonraki bölümde her bir adımı ayrı ayrı inceleyeceğiz.

- Trafiğin Aynalanması

- Aynalanan ağ trafiği içerisinde tek bir çağriya ait SIP ve RTP trafiğinin diğer çağrılardan ayrıştırılması

- Ayrışırıllan SIP paketinin kiracısının belirlenmesi

- SIP paketinin ayrıştırılarak çağrıya ait ayrıntılı görüşsme detayının (CDR) oluşturulması

- Çağrı detayına ait RTP paketlerinin içindeki verinin RAW formatında tek bir dosyaya çevrilmesi

- RAW dosyasının, SDP paketinin içerisinde belirtilen çözücüye göre WAV formatına çevrilmesi

- Kayıtlara kullanıcı erişim ara yüzlerinin oluşturulması

\subsection{Sunucu trafiğinin belirtilen işi yapacak sunucuya aynalanması}

Kullanıcıların dahili hatları ve dış operatörden gelen çağrıların medya geçiti üzerinden akan ağ trafiği anahtarlar ve TAP cihazları aracılığıyla, ağ trafiğinden ses kaydını ve çağrı detaylarını ayrıştıracak sunucuya aynalamaktır. Anahtar üzerinden aynalama yapılarak medya sunucusunun trafiği aynalama sunucusuna gönderilmiştir.

Sunucu tarafinda ağ trafik yakalaması için $\mathrm{C} / \mathrm{C}++$ kütüphanesi olarak çokça kullanılan libpcap kütüphanesi ile aynalanan paketler yakalanmaktadır. Libpcap, ağ paket yakalama sistemlerine üst düzey bir arayüz sağlayan açık kaynaklı bir kütüphanedir ve Tcpdump Grubu tarafindan korunmaktadır [35, 36].

Aynalama sunucusunda paket yakalama adına bir dizi işlem yapılmaktadır. Bunlar ağ ara yüzünün belirlenmesi, filtre oluşturulması, filtreye uygun paketlerin yakalanması, ve paketlerin işlenmesidir. Sunucuda test aşamasında Linux Centos 7 İşletim sistemi kullanılmıştır. Linux çekirdek versiyonu olarak 3.2 den yüksek olan tercih edilmiştir. 3.2 den önceki versiyonlarda Tepocket_V3 özelliği bulunmamaktadır. Bu özellik ethernet kartının paket yakalama hızını artırıp işlemci kullanımını azaltmıştır. Bu sayede paket kayıpları olmaksızın paketler yakalanmıştır.

Aynalanan paketlerin yakalanmasında problem yaşanmaması için özelleşmiş Ethernet kartları mvcuttur (Nopatec marka bu işler için özel olarak üretilmiştir) fakat yaptığımız testlerde dört portlu herhangi bir sistemle gönderilen ethernet kartını port birleştirme özelliği kullanarak birleştirdik ve herhangi bir problem olmadan kullanabildik. Yapılan testlerde paketler kayıpsız ve başarılı şekilde yakalanmıştır.

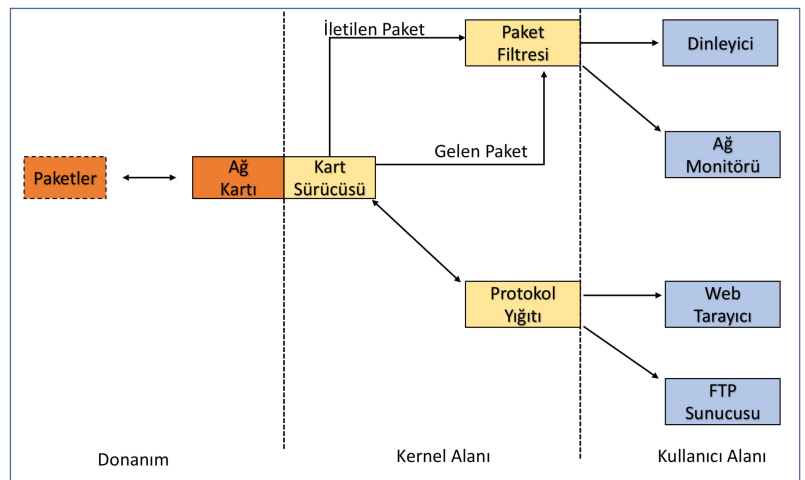

Şekil 4. Paket yakalama işlem adımları

\subsection{SIP ve RTP paketlerinin çağrı bazlı ayrıştırılması}

Aynalanan ağ trafiği içerisinde birçok çă̆rı ayrılan sunucuya akmaktadır. Bu çağrılardan tekil olarak her bir çağrıya ait SIP ve RTP trafiğinin diğer çağrılardan ayrıştırılması gerekmektedir. Bu aşamada aynalama yöntemi ile alınan paketlerdeki SIP protokolünde ki veriler ile çağrı bazında ayrıştırma yapılmalıdır. SIP protokolünü incelendiğinde çağrıların INVITE komutu ile başlayıp BYE komutu ile bitmekte olduğu gözlemlenmiştir. Şekil 5'da örnek bir SIP çağrı akış örneği mevcuttur.

Öncelikle INVITE komutu ile başlayan çağrının kimliğgi, call_id, bilgisi bulunabilir ve bu call_id ile eşleşen tüm komutlar belirlenir. Bu sayede bir çağrının oturumu elde edilmiş olmaktadır. Elde edilen bilgiler sayesinde RTP paketlerinde eşleşme yapılmaktadır.

\subsection{Ayrıştırılan SIP paketinin kiracısının belirlen- mesi}

SIP ve RTP paketlerinin ayrıştırılması yapıldıktan sonra bu çağrının hangi kiracıya ait olduğu belirlenecektir. Santral sisteminde her kiracı bir adet abone numarası ile temsil edilmektedir. Santral veri tabanında hangi harici hatların hangi kiracıya ait olduğu bilgisi tutulmaktadır. Gelen çağrılarda SIP başlığında kiracı bilgisi de taşınarak gelen 
Arayan: $101-3129114200$

A

INVITE sip:05077329364

1---d8754z-;rport

ontact: \&lt;sip:101-31291 14200@192.168.0.33:56124;rinstance=42ce18a19143a921 \&gt; To: \&lt;sip:05077329364@185.88.7.25:5060\&gt;

rom: \&quot;101-3129114200\&quot;\&lt;sip:101-3129114200@185.88.7.25:5060\&gt;;tag=a76c3705 Call-ID: ZGYxZmM2NmYyNTUwZGFkZTRhZGVIMjE INTIINTYxZTI.

CSeq: I INVITE

VIE, CANCEL, OPTIONS, BYE, REGISTER, SUBSCRIBE, NOTIFY,

EFER, INFO, MESSAGE

Content-Type: application/sdp

User-Agent: 3CXPhone 6.0.26523.0

$s=3 \mathrm{cxVCE}$ Audio Cal

$=$ IN IP4 192.168.0.33

m=audio 40046 RTP/AVP 08310

a $=$ rtpmap: 3 GSM $/ 8000$

a-rtpmap:101 telephone-event $/ 8000$

a-fmtp:101 0-15

$a=p$ time: 20

$=$ sendre

$m=$ video 40022 RTP/AVP 34

$c=I N$ IP4 192.168.0.33

$\mathrm{a}=$ fmtp: $34 \mathrm{QCIF}=1 ; \mathrm{CIF}=1 ; \mathrm{SQCIF}=1 \cdot \mathrm{CIF} 4=1$

Şekil 5. SIP mesaj içeriği

çağrının hangi kiracıya ait olduğu tutulmaktadır. Bu işlem yanında gelen çağrıda ki aranan numara bilgisi sayesinde kiracı belirlenebilmektedir. Giden çağrı yönünde çağrıyı santral başlattığı için kiracı bilgisi zaten tutulmaktadır.

\subsection{SIP paketinin ayrıştırılarak çağrıya ait ayrıntılı görüşme detayının (CDR) oluşturulması}

SIP paketleri ayrıştırılan çağrıların CDR (Call Detail Records) kayıtlarının oluşturulması işlemi yapılaması gerekmektedir. Daha önceki işlemlerde SIP paketleri ayrıştırılarak çağrı bazında ayrım yapılmıştır. Bu aşamada ise elde edilen bilgiler ile CDR oluşturulması işlemine başlanmıştır. CDR kayıtlarında arayan numara, aranan numara, arama zamanı, Call-ID, arama süresi ve aramanın durumu bilgileri tutulmaktadır. Bu işlem sayesinde kiracıların web ara yüzünde arama bilgileri gösterilebilecektir. Elde edilen veriler santral veri tabanına yazılmaktadır. CDR verileri veri tabanında saklanmaktadır.

\subsection{RTP paketlerindeki verinin ayrıştırılıp RAW for- matında tek bir dosyaya çevrilmesi}

SIP çağrılarında çağrıların kod çözücülerinin ve RTP paketlerindeki SSRC (Synchronization source) belirlenmesi başarılı bir çağrı oluşması için gereklidir. Bu aşamada çağrı detayına ait RTP paketlerinin içindeki verinin kod çözücülerinin türü ve SSRC değerine göre ayrıştırılıp, RAW formatında tek bir dosyaya çevrilmesi gerekmektedir. SIP görüşmelerinde çağrılar farklı kod çözücülerde yapılabilinir. Sahip olunan bant genişliğine göre kod çözücü değiştirilmelidir. Sıkıştırma oranı arttıkça seste kalite algısı düşmekte fakat kullanılan bant genişliği ihtiyacı azalmaktadir.

SIP çağrısında kullanılan kod çözücü bilgisi yapılan görüşmenin kullanıcının dinleyeceği format olan WAV formatına dönüştürmede de gereklidir. Çağrının kodek türü RTP paketlerindeki SSRC'de RTP kimliği belirleme sırasında kullanılan SEQ komutunda belirlenmektedir (Şekil 8). Kullanılan telefonların desteklediği kod çözücü listesi ise STP paketinde listelenmektedir. SDP paketinde RTP paketlerin akacağı portlar karşı tarafa bildirilmektedir. Bu sayede kullanıcılar RTP akışı için hangi portları dinleyeceklerini bilmektedirler. Son aşamada elde edilen RTP paketler RAW formatında kaydedilmektedir.

\subsection{Oluşturulan RAW dosyasının kod çözücüye göre WAV'a çevrilmesi}

Oluşturulan RAW dosyasının, SDP paketinin içerisinde belirtilen kod çözücüye göre dönüşüm yaptırılarak, dinlenebilecek format olan WAV a çevrilmesi işlemi bu aşamada gerçekleştirilecektir. Daha önce ki adımlarda RAW formatında kaydedilen veriler WAV formatına çevrilerek kullanıcıların dinleyebileceği bir formata çevrilmiş olacaktir.

Bir SIP görüşmesinde gelen ve giden çağrı için iki farklı RAW formatında ses kaydı oluşmaktadır. Bu kayıtlar kod çözücülerine göre farklı araçlar ile WAV formatına dönüştürülmektedir. Alaw ve Ulaw formatları için Linux SOX programı, G 729 kodeği için ise Mpeg123 G729 Translater kullanılmıştır. Daha sonra elde edilen bu iki kayıtın birleştirilmesi işlemi yapılmaktadır. Burada önemli olan ise kayıtların senkron şekilde ilerlemesi gerekmektedir. Bazı kayıtlarda senkron kayması yaşanmaktadır. Bunun önüne geçmek için ise Mark değerlerinde ki kayıt başlama zamanlarının aynı olması gerekmektedir. Mark değeri, Ses görüşmesinde gelen ve giden çağrıların ayrı ayrı kayıt edilmesinde ve her iki taraf içinde ilk RTP paketine bir işaret olarak konulmasına verilen addır. Bu sayede ilk paketi bilinmekte ve her mark değeri arasında ki zaman farkı da senkron kaymasını göstermiş olmaktadır. Bu kayma değerine göre konuşma başına süre ekleyerek veya çıkararak eşit hale getirilmektedir. İlerde olan kayıtta gerektiği kadar bekleme eklemesi yapılarak değerler eşitlenmektedir. Bu işlemden sonra oluşan her iki WAV formatlı kayıt SOX ile birleştirme işlemi yapılarak kayıt edilmektedir. Kayıt edilen çağrının dosya ismi oluşan çağrının CDR kayıtlarına da eklenmektedir.

\subsection{WAV dosyasının kullanıcıya sunulması ve de- polanması}

Oluşturulan ses dosyasının çağrı detayındaki kayıtla eşleştirilerek, abonenin kendi ara yüzünde görüşme detayıyla birlikte gösterilmesi işlemi ile işlemler sonlandırılır. Alınan ses kaydı ile CDR bilgilerinin kullanıcı ara yüzünde gösterilmesi işlemi yapılmalıdır. Birleştirme işleminden sonra ses kayıtlarının hangi çağrıya ait olduğu bilgisi veri tabanında tutulmaktadır. Kullanıcı web ara yüzüne girdiğinde görmüş olduğu ses kaydı ve CDR kayıtları santral veri tabanından alınarak kullanıcı ara yüzüne getirilmektedir. Kiracı bilgisi de CDR kayıtlarından bulunmaktadır. Web ara yüzünde kullanıcıların kayıtlarının başkası tarafindan tahmin edilerek dinlenmemesi için şifrelenerek ara yüze getirilmektedir. Bu sayede web ara yüzünde kullanıcılar mevcut web yolunu değiştirerek başka kullanıcıların ses kayıtlarını dinlemesinin önüne geçilmektedir.

Oluşturulan WAV dosyalarının arşivlenmesi adına, elde edilen ses kayıtlarının Telekom alanında BTK'nın belirlediği mevzuata göre ve genel hukuki zorundalıkları 


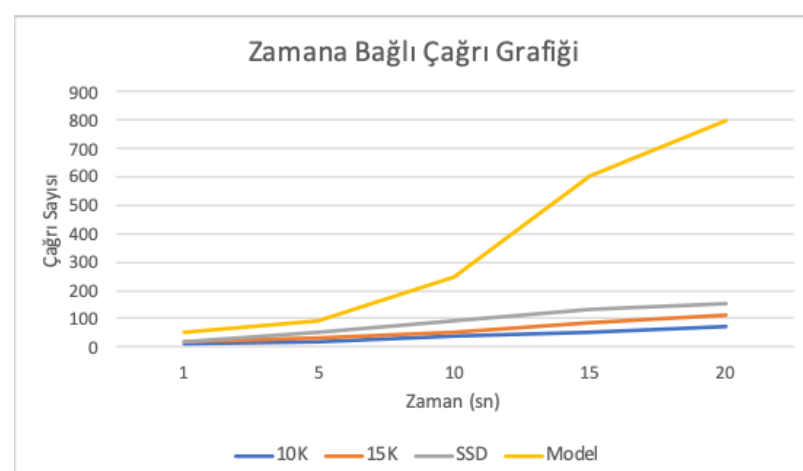

Şekil 6. Kayıt ve çağrı işlemlerinin ayrıştırılmış yürütüldüğü model performans testleri

da düşünülerek 3 ay süre ile arşivlenmesi sağlanacaktır. Elde edilen ses kayitları bu süre boyunca NAS serverda tutulmakta ve kullanıcının ihtiyacı olması halinde arşivden çekilmesi sağlanmaktadır. 3 ay sonunda ses kayıttları silinmektedir. Arșivleme NAS serverda Kiracı adı/Yıl/Ay/Gün/seskaydı_adı şeklinde saklanmaktadır. NAS serverda ses kaydı kaybı yaşanmaması için RAID 50 formatında harici disk yerleşimi yapılmış bir yapı düşünülmüsstür. Toplam kullanılabilecek alan 176 Terabayt olmaktadır. Bu sayede harici disklerin bir tanesinde problem olsa dahi kayıp olmamakta ve sistem çalışmaya devam etmektedir.

\subsection{Performans sonuçları}

Sunulan model ile elde edilen kayıt işlemlerine bakıldığında alınan performans sonuçları aşağıda belirtilmiştir. Öncelikli olarak Asterisk üzerinde başlatılabilen çağrı sayısı test edilmiştir. Şekil 6 de verilen zamana bağlı çağrı grafiğinde daha önce ses kaybı ve bozulma yaşamadan 150 çağrıya kadar çıkılabilirken yeni sunulan ayrıştırılmış model ile 800 çağrıya kadar sorunsuz çıkılabilmektedir. Bu şekilde 5,3 kata kadar kapasite artışı gözlemlenmiştir.

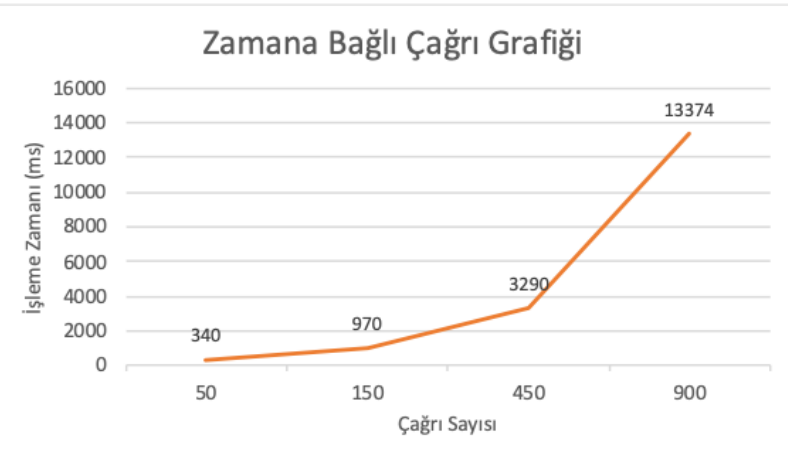

Şekil 7. Kayıt işlemlerinin sisteme işlenmesi performans testleri

Ayrıca yapılan çağrı kayıtlarının yeni model ile ne kadar süre gecikmeli olarak işlenebildiği bazı senaryolar için önemli bir faktör olabilir. Özellikle çağrı adetlerinin artmasıyla kayıt yapan sunucuların her bir dakikalık kaydı ne kadar süre gecikmeli sunduğu üzerine yaptığımız test Şekil 7'da sunulmuştur. Bu verilere göre 50 çağrı için kaydın sisteme düşme süresi çağrı sonlandıktan sonra $340 \mathrm{~ms}$,
900 çağrıya çıkıldığında 13 saniye civarlarında gecikme yaşanabilmektedir. Genel olarak ses kaydının kullanıcıya sunulma süreci çok aciliyet gerektirmese de ve kullanıcılar ses kayıtlarını ulaşma adına çok acil bir geri dönüş beklemese de, ileride yapabileceğimiz ses üzerine işlemler ve analizi ile anlık karar içeren süreçlerde gerekli olabilir. Sunulan modelde ses kayıtlarının işleme adına ayrıntılı süreçlerindeki zamanlamalara baktığımızda üç temel aşamada bu çalışmaları incelememiz mümkündür. İlk aşama paket birleştirme ve parçalar halinde gelen ses paketlerinin toplanmasıdır. İkinci aşama bu ses paketlerinin RAW formatından sesformatı olan WAW formatına dönüşümüdür. Son aşama ise eşleştirme sürecidir. Bu süreçlerin birbirilerine göre hızları verilen bir paketi boyut bağımsız olarak, paket birleştirme süreci 2 zaman birimi, RAWWAW dönüştürme süreci 6 zaman birimi, eşleştirme süreci 2 zaman birimi almaktadır. En uzun olan kısım dönüştürme kısmıdır. İleride iyileştirme adına öncelikli olarak bu kısım hedeflenebilir. Ayrıca kayıt işlemlerinde ölçekleme adına yatay ölçeklemeye izin veren yapı da oluşturulmuş ve istenildiğinde kayıt işlemlerinin birden fazla sunucuyla sağlanabildiği bir model sunulmuştur Şekil 8 .

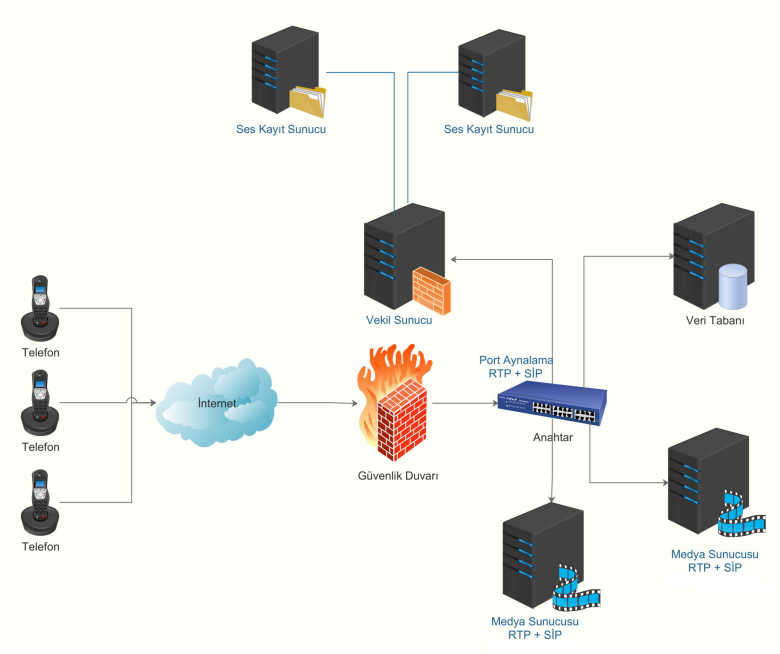

Şekil 8. Kayıt işlemlerinin çoklu sunucuyla başarılması.

\section{Sonuç ve Gelecek Çalışmalar}

İnternetin hemen hemen her yerde çok yaygın olması, kullanışlı ve ucuz olan VoIP teknolojisinin çok hızlı bir şekilde yaygınlaşmasının sonucu olarak telekomünikasyon hizmetlerinden biri olan ses kayıt işlemlerinin de bu teknoloji içerisinde yapılması gerekliliğini ortaya çıkarmıştır. Hali hazırdaki VoIP işlemlerinin I/O ağırlıklı işlemler sırasında o anki iletişim akışında bozulmalara neden olması nedeniyle, iletişımin I/O ağılıklı işlemler düşünülerek yeniden tasarlanması gerekliliği ortaya çıkmıştır. Bu kapsamda yaptığımız çalışmalar sonucu kayıt işlemlerini iletişim akışından ayırarak farklı sunucular üzerinde gerçeklenmesini sağlayan bir model sunduk. Bu yapılan işlem ile bozulmalara yol açan seviyelerin 150 anlık çağrıdan 800 çağrıya çıkmasını sağladık ve bu şekilde 5.33 kat bir hızlanma elde ettik.

$\mathrm{Bu}$ çalışma ile ileride yapılabilecek ses kayıtları üzerinden analizler, anlık bildirimler ve çıkarımlar, makine öğren- 
mesi ile iletişim anında yaşanabilecek sorunların (müşteri memnuniyetsizliğinin anlaşılması, sinir veya küfür içeren ifadelerin tespiti, vb. gibi) gerçek zamanlı tespiti, sesten yazıya döküm gibi bir çok hizmet ve yeni ürün için imkan sağlanmış olmaktadır.

\section{Teşekkür}

Bu proje Sanayi Bakanlığı' nın Ar-Ge merkezi bünyesinde sağlanan desteklerle ve TÜBİTAK TEYDEB 7180242 numaralı 1507 Kobi-ArGe projesi kapsamında gerçekleştirilmiştir.

\section{Kaynakça}

[1] SIP: Session initiation protocol, RFC 3261, http://www.ietf.org/rfc/rfc3261.txt (Erişim Tarihi: 15.05.2019).

[2] G.711 kodek bilgileri, https://www.itu.int/rec/T-RECG.711/en (Erişim Tarihi: 15.05.2019).

[3] G.723 kodek bilgileri, https://www.itu.int/rec/T-RECG.723.1/en (Erişim Tarihi: 15.05.2019).

[4] G.726 kodek bilgileri, https://www.itu.int/rec/T-RECG.726/en (Erişim Tarihi: 15.05.2019).

[5] G.729 kodek bilgileri, https://www.itu.int/rec/T-RECG.729/en (Erişim Tarihi: 15.05.2019).

[6] Haloncn, T., Melero, 1. and Romero, J. 2002. GSM, GPRS and EDGE Performance: Evolution Toward 3GNMTS, Wiley \& Sons.

[7] Järvinen, Kari. 2000. Standardisation of the adaptive multi-rate codec, 10th European Signal Processing Conference. IEEE, 2000.

[8] 3GPP TS 26,171: AMR Speech Codec; General description. https://www.3gpp.org/, (Erişim Tarihi: 15.05.2019).

[9] 3GPP TS 26.193 : AMR Wideband Speech Codec: Source Controlled Rate operation, https://www.3gpp.org/DynaReport/26193.htm, (Erişim Tarihi: 15.05.2019).

[10] Hoene, Christian, Holger Karl, and Adam Wolisz. 2004. A perceptual quality model for adaptive VoIP applications, Proceedings of SPECTS, Vol. 4.

[11] Chuah, C.-N. and Katz, R. H. 2002. Characterizing packet audio streams from internet multimedia applications. In Proceedings of IEEE International Conference on Communications (ICC 2002), volume 2, pages 1199-1203.

[12] Fukui, M., Shimauchi, S., Kobayashi, K., Hioka, Y., Ohmuro, H. 2014. Acoustic echo canceller software for VoIP hands-free application on smartphone and tablet devices. IEEE Transactions on Consumer Electronics, 60(3), 461-467.

[13] ETSI, EG. 202 396-1,Speech and multimedia transmission quality (STQ). 2011.

[14] Sfairopoulou, Anna, Carlos Macián, and Boris Bellalta. 2007. Dynamic measurement-based codec selection for VoIP in multirate IEEE 802.11
WLANs.Proceedings of the 8th COST 290 Management Committee Meeting.

[15] Worrall, A.; Carter, B.;Widley, G. 2008. U.S. Patent No. 7,411,946. Washington, DC: U.S. Patent and Trademark Office.

[16] Zhang, Jian, and Andrew Moore. 2007. Traffic trace artifacts due to monitoring via port mirroring. Workshop on End-to-End Monitoring Techniques and Services. (pp. 1-8). IEEE.

[17] M. Arlitt and C. Williamson. 2005. An Analysis of TCP Reset Behaviour on the Internet. ACM Computer Communication Review, Vol.35, No.1 pp.37-44.

[18] M. Arlitt, B. Krishnamurthy and J. C. Mogul. 2005. Predicting short-transfer latency from TCP arcana: Atrace-based validation. ACM/USENIX IMC'05, pp.213-226, Oct. 19-21.

[19] K.T. Chen, C.Y. Huang, P. Huang and C.L. Lei. 2006. Quantifying Skype User Satisfaction. ACM Sigcomm 2006, pp.399-410, Sept. 12-14.

[20] Callado, A. C., Kamienski, C. A., Szabó, G., Gero, B. P., Kelner, J., Fernandes, S. F., and Sadok, D. F. H. (2009). A survey on internet traffic identification. IEEE Communications Surveys and Tutorials, 11(3), 37-52.

[21] Barker, Kirk, and Darrell D. Roberts.2006. Voice over IP telephone recording architecture. U.S. Patent No. 7,054,420.

[22] Kouretas, Stephen, et al. 2011. Method and apparatus for voice-over-IP call recording and analysis. U.S. Patent No. 7,873,035.

[23] Martin, II James Paul. 2013. Distributed record server architecture for recording call sessions over a VoIP network. U.S. Patent No. 8,422,641.

[24] Clingenpeel, James E., and Brent E. Henry. 2012. Event monitoring and collection. U.S. Patent No. $8,122,122$.

[25] Carroll, Robert, Darrell Roberts, and Theodore Edwards. 2009. System and method for on-demand recording. U.S. Patent No. 7,499,530.

[26] Silva, Christopher Anthony. 2013. Method for recording mobile phone calls. U.S. Patent No. 8,428,559.

[27] Othmer, Konstantin. 2012. Selectively buffering voice data at a server during a voice communication session. U.S. Patent No. 8,185,143.

[28] Ilan, Tomer, Eran Halbraich, and Ilan Yosef. 2018. Method and system for monitoring and recording voice from circuit-switched via a packet-switched network. U.S. Patent No. 7,333,445.

[29] Beuran, Razvan, and Mihai Ivanovici. 2004. Userperceived quality assessment for VoIP applications. CERN-OPEN-2004-007.

[30] Van Blarcum, Karen. 2004. Passive VoIP Call Recording. White Paper, http://www. audiocodes. com/library/type 39591 (Erişim Tarihi: 15.05.2019). 
[31] Gao, Fuxiang, Yanfang Gao, and Miao Li. 2009. Design and implementation of web-based voip recording management system. International Conference on Information Science and Engineering. IEEE.

[32] Cordero, José Manuel, Manuel Dorado, and José Miguel de Pablo. 2012. Automated speech recognition in ATC environment. Proceedings of the 2nd International Conference on Application and Theory of Automation in Command and Control Systems. IRIT Press.

[33] SDP: Session Description Protocol, RFC 3261, https://tools.ietf.org/html/rfc4566 (Erişim Tarihi: 15.05.2019).

[34] RTP: Real-Time Transport Protocol, RFC 3550, https://tools.ietf.org/html/rfc3550 (Erişim Tarihi: 15.05.2019).

[35] libpcap kütüphanesi, https://www.tcpdump.org/ (Erişim Tarihi: 15.05.2019).

[36] Programming with pcap, https://www.tcpdump.org/pcap.html (Erişim Tarihi: 15.05.2019). 